\title{
Assessment, care and management of patients with a red eye
}

Watkinson S, Seewoodhary R (2017) Assessment, care and management of patients with a red eye. Nursing Standard.

Date of submission: 22 May 2017; date of acceptance: 1 August 2017. doi: 10.7748/ns.2017.e10902

Susan Watkinson

Associate lecturer, College of Nursing, Midwifery and Healthcare, University of West London, West London campus, Brentford, Middlesex, England

Ramesh Seewoodhary

Senior lecturer, College of Nursing, Midwifery and Healthcare, University of West London, London, England

Correspondence

sue.watkinson@uwl.ac.uk

Conflict of interest

None declared

Peer review

This article has been subject to external double-blind peer review and checked for plagiarism using automated software

Online

For related articles visit the archive and search using the keywords. Guidelines on writing for publication are available at: rcni.com/writeforus

\footnotetext{
Abstract

Red eye is a common ocular presentation in primary care, and there are several challenges that may be encountered when caring for such patients. The main ocular conditions that can give rise to a red eye are: primary acute angle closure glaucoma, acute iritis, dry eye, chronic blepharitis and conjunctivitis. Red eye can be classified as sight-threatening or non-sight-threatening. When red eye is associated with pain, photophobia, watering and blurred vision, it is potentially sight-threatening and must be addressed urgently. Therefore, it is vital for healthcare practitioners to be able to undertake a careful assessment of the patient and make an accurate diagnosis early. However, many patients presenting with a painless red eye and normal vision usually recover well. This article provides an overview of the common causes of red eye encountered in general practice or an eye clinic. It discusses the nurse's role in the care and management of patients with a red eye, with reference to patient assessment, the skills required to make an accurate diagnosis, treatment and health promotion.
} 


\section{Keywords}

blepharitis, conjunctivitis, eye conditions, health promotion, iritis, ocular health, ophthalmology, primary acute angle closure glaucoma, red eye

RED EYE is a common ocular presentation in primary care. It can be classified as sight-threatening or non-sightthreatening (Batterbury et al 2009). In this article, primary acute angle closure glaucoma (PAACG) and acute iritis will be considered sight-threatening conditions, while dry eye, chronic blepharitis and conjunctivitis will be considered non-sightthreatening conditions. Effective recognition of the signs and symptoms of all these conditions enables healthcare practitioners to distinguish between a sight-threatening and non-sight-threatening ocular condition and is central to successful management and care of the patient (Watkinson 2013).

Knowledge of the main structures of the eye, shown in Figure 1, can assist the nurse to develop their skills in ocular observation and effective assessment of the patient presenting with a red eye. This article is aimed at ophthalmic nurses, general nurses and all allied healthcare practitioners working in hospital, particularly those in emergency departments, GP surgeries and community settings. It provides an overview of the nurse's role in the assessment, care, management and health promotion of patients presenting with a red eye. It also discusses the skills and responsibilities involved in establishing accurate diagnosis and making prompt referral for appropriate treatment to relieve ocular pain, restore vision or prevent potential sight loss.

\section{Figure 1. Diagram of the main structures of the eye}

[Ed note: figure to be re-used from Watkinson 2013]

\section{Assessment}

History-taking is an important component of assessing a patient with red eye. Box 1 lists questions that healthcare practitioners could ask the patient as part of history-taking. Listening attentively and asking appropriate questions related to vision are essential to effective patient assessment. The nurse should assess and record the visual acuity of each eye - a medico-legal requirement - to establish the main visual complaint, duration of the condition and its effect on the patient's quality of life (Williamson and Seewoodhary 2013). It is important to ask the patient whether the effect on their vision is transient, deteriorating, or improving. Using a pen torch is best practice and recommended for examining the anterior segment of the eye and making observations (Watkinson 2013).

\section{Box 1. History-taking questions in relation to the symptoms of red eye}

Duration

- How long has the redness been present?

- Is the eye painful or sore?

- Does the eye itch?

- Does the eye water?

- Is there any light sensitivity?

- Is there a past history of red eye?

- Is there any yellow purulent discharge or crustiness?

- Is the vision blurred?

- Does the eye feel dry and burning? 
Onset

- Is it unilateral or bilateral? When did it come on?

- Was that sudden or gradual?

- Is it constant itchiness?

- Is it worse when outdoors?

- When did you notice that? What caused it?

- Is it worse on waking up? When did you notice it? Describe what you see.

- How long have you noticed it?

(Adapted from Watkinson 2013) [Q1. I couldn't find this information in Watkinson 2013 - is it from another source?]

Sight-threatening red eye conditions

Primary acute angle closure glaucoma

PAACG (Figure 2) is a condition in which there is a sudden increase in intraocular pressure (IOP). This results from obstruction of aqueous outflow by partial or complete closure of the drainage angle by the peripheral iris (Bowling 2015). The normal IOP is between 14 and 21mmHg (Yanoff and Duker 2013). In PAACG, it could rise to 70mmHg, causing damage to the optic nerve head (Yanoff and Duker 2013). This is an ocular emergency and should be treated immediately to prevent sight loss to both eyes, since it is potentially a bilateral disease. The signs and symptoms of PAACG are listed in Box 2 .

Figure 2. Primary acute angle closure glaucoma

[Ed note: figure to be re-used from Watkinson 2013]

\section{Box 2. Signs and symptoms of primary acute angle closure glaucoma}

- Dusky, congested red eye

- Hazy cornea

- Limbus - marked ciliary injection

- Shallow anterior chamber

- Congested and dull iris

- Oval-shaped and unreactive pupil

- Pupillary block

- Vision is reduced

- $\quad$ Seeing haloes around lights

- Severe ocular pain radiating to the forehead, lacrimation and photophobia

- Headache and nausea

- Abdominal discomfort

(Adapted from Watkinson 2013)

Pre-disposing factors for PAACG include (Bowling 2015):

- Older age with hypermetropia (long-sightedness). Older women are more at risk than men.

- Sustained pupil dilation, which may be triggered by instilling dilating drugs such as $1 \%$ atropine sulfate. 
- Occasional excessive pupil dilation, which may be precipitated by low light or emotions such as fear, anxiety, stress and sadness. [Q2. bullet points reworded - please check that your meaning has been preserved]

\section{Treatment and clinical management}

During an acute episode of PAACG, the patient usually experiences anxiety, distress and nausea (Watkinson 2013). Providing reassurance that ocular pain will subside once the IOP is under control is comforting and reduces anxiety. The patient should be encouraged to rest in a quiet environment (Bowling 2015).

Treatment of PAACG varies according to hospital policy. It is important to record baseline observations of visual acuity and IOP. First, 500mg intravenous acetazolamide, a carbonic anhydrase inhibitor, is administered to reduce IOP by decreasing aqueous production. After 20 minutes, 2-4\% pilocarpine eye drops are instilled into the affected eye to open up the drainage system by constricting the pupil. This also reduces the IOP. $0.25 \%$ timolol maleate eye drops, a beta-blocker, and $\mathbf{0 . 5 \%}$ apraclonidine eye drops [Q3. couldn't find $0.5 \%$ apraclonidine in the BNF - is this correct?], an alpha-adrenergic agonist, are also instilled to achieve improved outcomes [Q4. is the information here an example of the treatment that could be used for PAACG? Suggest clarifying since previously it states that treatment varies according to hospital policy] (Bowling 2015). Beta-blockers should be used with caution because they are contraindicated in patients with chronic obstructive pulmonary disease or cardiovascular disease (British National Formulary 2017). 0.1\% dexamethasone eye drops are instilled to reduce inflammation and congestion. Artificial teardrops are also used to provide comfort. An antiemetic may be administered as required. The IOP is monitored in the emergency department. The ultimate surgical treatment is cataract surgery or laser iridotomy to improve drainage of aqueous humour, thus lowering IOP (Azuara-Blanco et al 2016).

\section{Acute iritis}

Acute iritis is an acute inflammation of the iris (Figure 3). The cause is usually unknown, but may be associated with underlying systemic conditions, such as rheumatoid arthritis, Crohn's disease, Still's disease, and ankylosing spondylitis. One or both eyes can be affected (Yanoff and Duker 2013) and the condition often progresses considerably before an accurate diagnosis is made (Batterbury et al 2009). Box 3 lists the signs and symptoms of acute iritis.

There is a chronic form of iritis that can occur, but with less pain and redness than in acute iritis. Chronic iritis can be caused by sarcoidosis, heterochromia and tuberculosis (Yanoff and Duker 2013). Such patients require regular follow-up in an eye clinic.

\section{Figure 3. Acute iritis}

[Ed note: figure to be re-used from Watkinson 2013]

Box 3. Signs and symptoms of acute iritis

- Red eye with marked ciliary injection

- Lids may appear swollen in some patients

- Cornea: may be clear but has keratic precipitates (clumps of inflammatory cells on the corneal endothelium)

- Anterior chamber: inflammatory cells and flare (a proteinaceous exudate in the anterior chamber) and possible hypopyon (a collection of inflammatory cells settling in the inferior anterior chamber)

- Iris: muddy and dull

- Pupil: small and sluggish reaction, and may be irregular from posterior synechiae (formation of adhesions between the iris and the lens)

- Dull pain at the back of the eye, lacrimation, photophobia, blurred vision 
- Vision: normal initially but becoming blurred if severe

(Seewoodhary 2009)

\section{Treatment and clinical management}

Following diagnosis, treatment is commenced with dilating drops such as $1 \%$ cyclopentolate hydrochloride to prevent adhesion and relieve ciliary spasm and pain. Corticosteroid eye drops such as $0.5 \%$ dexamethasone [Q5. couldn't find $\mathbf{0 . 5 \%}$ dexamethasone in the BNF - is this correct?] are prescribed to treat the inflammation and promote healing [Batterbury et al 2009). A subconjunctival injection of mydricaine is given to patients who have developed posterior synechiae, to break adhesions between the posterior iris and lens surface. Delay in treatment usually results in adhesion formation. Systemic corticosteroids and immunosuppressants are reserved for sight-threatening disease (Batterbury et al 2009).

It is important that patients presenting with recurrent acute iritis have baseline investigations undertaken. These include erythrocyte sedimentation rate, full blood count, serum angiotensin-converting enzyme level, syphilis serology, human leucocyte antigen typing, and chest and sacroiliac joint $\mathrm{X}$ rays to establish evidence of underlying systemic disease. The patient may require medical referral for further investigation and management (Batterbury et al 2009).

The nurse should explain to the patient that a dilated pupil causes blurred vision, thus driving is not recommended until their eye has fully recovered. Regular attendance at an eye unit for assessment and monitoring of the condition is essential until this has resolved. Counselling about the recurrent nature of the condition and the need for treatment of recurrent episodes is important to prevent serious long-term complications (Shaw and Lee 2016).

Non-sight-threatening red eye conditions

Blepharitis

Blepharitis is a chronic inflammatory condition affecting the eyelid margin (Din and Patel 2012), and accounts for 5\% of all ophthalmological conditions presenting in primary care (National Institute for Health and Care Excellence 2015). The eyelid margins are lined with sebaceous glands that produce a thin, clear oily material contributing to tear film stability and corneal clarity. Unexplained inflammation of those oily glands may contribute to tear film instability and dry eyes [Q6. resulting in blepharitis?] (Din and Patel 2012). Box 4 lists the signs and symptoms of blepharitis.

\section{Box 4. Signs and symptoms of blepharitis}

- Asymptomatic

- Redness

- Itching

- Burning

- Crusting

- Stickiness and/or loss of eyelashes

- Tearing

- Light sensitivity (sometimes) [Q7. does this mean light sensitivity only occurs in some patients with blepharitis, or that it only occurs sometimes i.e. occasionally ?]

- Blepharospasm (spasm of the orbicularis muscle)

(Adapted from Yanoff and Duker 2013)

Blepharitis is classified as being anterior or posterior (The College of Optometrists 2016). Anterior blepharitis (Figure 4) is a common chronic bilateral inflammation of the lid margins (Riordan-Eva and Cunningham 2011). It is commonly caused by Staphylococcus aureus, seborrhoea and Demodex folliculorum (Din and Patel 2012). 


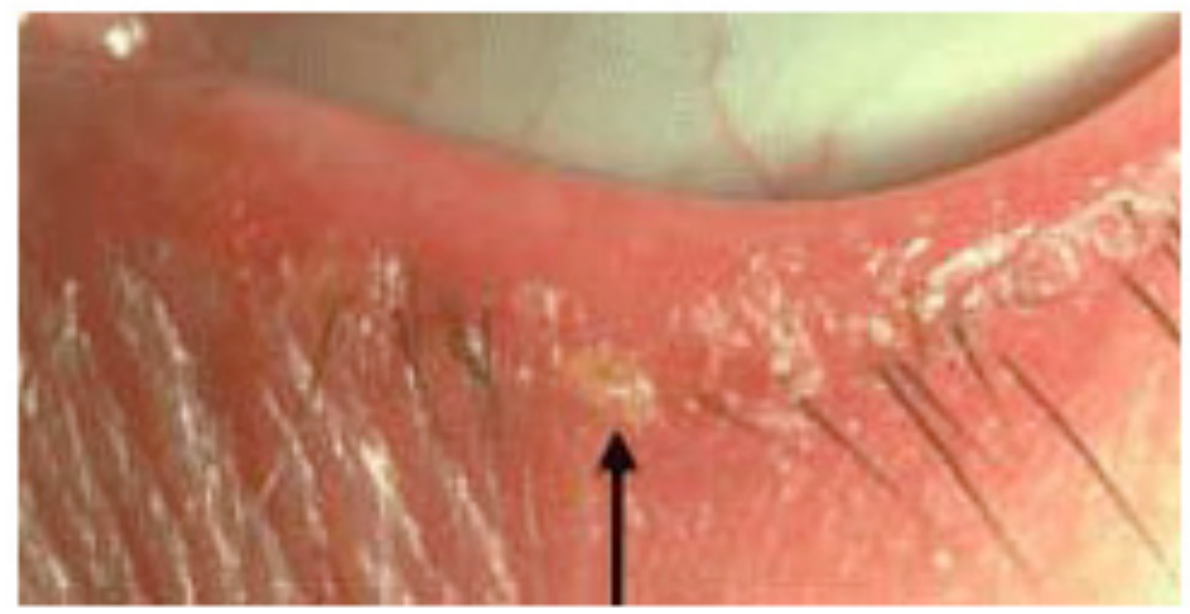

[Ed note: authors to obtain permission for use and send figure as separate jpg]

Posterior blepharitis (Figure 5) is caused by dysfunction of the meibomian glands, which are in the tarsal plate of the eyelid. There are usually 30-40 meibomian glands in the tarsal plate of the upper eyelid and 20-30 in the tarsal plate of the lower eyelid (Yanoff and Duker 2013). Thickening of the lipid composition of those glands leads to reduced delivery of oily secretion to the ocular surface. Tear film instability and dry eyes are common in posterior blepharitis (Yanoff and Duker 2013).

\section{Figure 5. Posterior blepharitis}

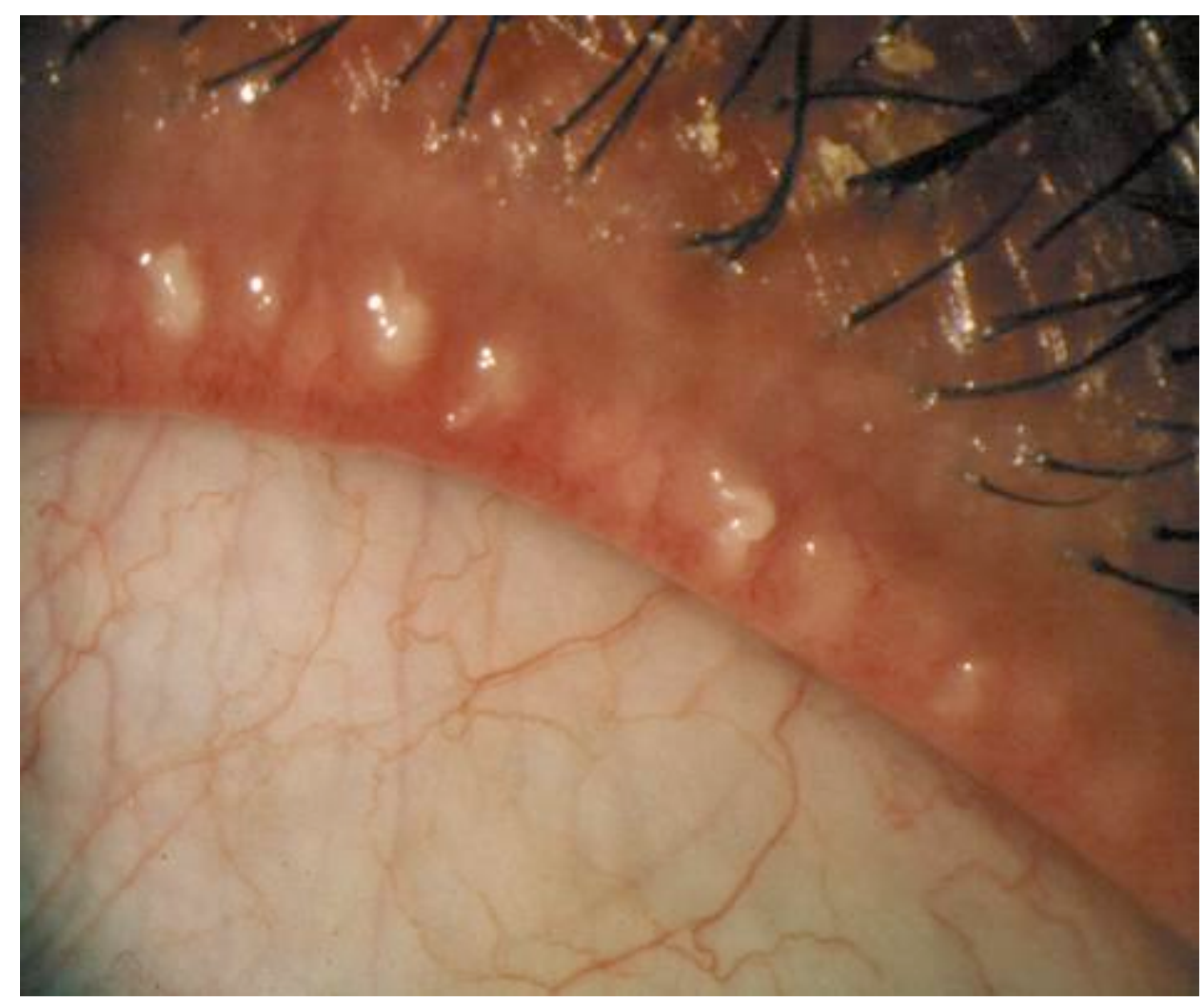

[Ed note: authors to obtain permission for use and send figure as separate jpg] 


\section{Treatment and management}

Lid hygiene is essential in the management of blepharitis and twice-a-day bathing of eyelids is required for patients with anterior blepharitis (Din and Patel 2012). The use of a warmed flannel to a closed eye is also recommended to loosen and soften the encrustations and secretions from the glands. This is often combined with warm compresses and eyelid massage, which reduce the bacterial load on the lid margins and improve the quality of meibomian gland secretions [Q8. what is meant by quality in this context (and below)?] (Jackson 2008).

Patients require instructions on lid hygiene and how to apply a warm compress using a flannel dipped in comfortably warm water to the closed eyelid for 5-10 minutes. Once the condition settles, patients are advised to continue with daily lid hygiene to prevent a recurrence. In the acute stage, an antibiotic ointment is prescribed, such as erythromycin, for application specifically to the lid margin to avoid corneal toxicity (Yanoff and Duker 2013). Patients with posterior blepharitis require long-term systemic antibiotics such as 20mg oral doxycycline. More recently, topical 1\% azithromycin [Q9. couldn't find 1\% azithromycin in the BNF - is this correct?] - an eye drop - has become an effective treatment for posterior blepharitis because it improves the quality of tears and gland secretion and provides overall symptom relief (Yanoff and Duker 2013).

Artificial teardrops are also recommended for ocular comfort. Healthy eating, including oily fish rich in omega 3, has been found to improve the quality of the meibomian secretion (Din and Patel 2012). Vitamin E is also beneficial in maintaining the integrity of the oily lid secretion. The use of a corticosteroid combined with antibiotics may be useful if the lid inflammation is severe. However, the patient should be monitored in an eye clinic for side-effects such as cataract, glaucoma and corneal thinning (Din and Patel 2012).

\section{Dry eye}

Dry eye is reduced tear flow and increased evaporation of tears that is characterised by ocular irritation and visual disturbance. Excess tearing can also be a symptom (Yanoff and Duker 2013). However, it can cause red eye and ocular surface disease, which may develop into more severe eye complications such as corneal ulceration and conjunctivitis (Foulks 2007). It ranges in severity from mildly irritating to severely disabling (Seewoodhary and Awelewa 2014). The incidence of dry eye ranges from $3 \%$ to $15 \%$ in patients aged over 50 years and to $17 \%$ in those over 80 years [Q10. please check these figures are correct - I couldn't find the $15 \%$ or $17 \%$ figures in the reference] (Schaumberg et al 2009). Dry eye is an under-recognised condition, which can affect the patient's quality of life because it reduces the ability to drive and read (Seewoodhary and Awelewa 2014).

Dry eye can affect any one of the three layers of the tear film, namely the outer lipid, middle watery and innermost mucin layers. Figure 6 shows the tear film layers, while Figure 7 shows a red eye caused by dry eye.

\section{Figure 6. Tear film layers}

(Watkinson 2014. Created by Mary Blood for Mike Roberts. Reproduced with the kind permission of M\&K Publishing) [Q11. is this correct?]

\section{Figure 7. Dry eye}

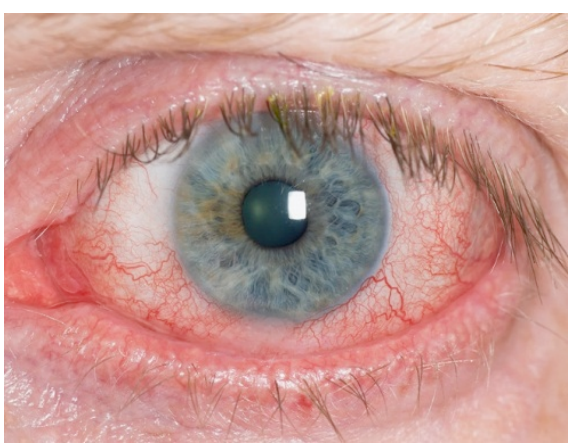


Patients experiencing dry eyes usually report burning, itching, foreign body sensation, stinging, dryness, photophobia, ocular fatigue and redness (Yanoff and Duker 2013). The condition is made worse if the patient also has anterior and/or posterior blepharitis. Posterior blepharitis is common in meibomitis, a condition where the meibomian oil glands become inflamed and infected (Törnquist 2012). The patient's history is classic [Q12. meaning unclear - could this be clarified / rephrased?], but holistic assessment is important because systemic diseases such as thyrotoxicosis, Sjogren's syndrome, diabetes mellitus, arthritis, lupus erythematosus, sarcoidosis, shingles or vitamin A deficiency are also known to lead to dry eyes (Yanoff and Duker 2013). Some medications may also cause poor tear secretion [Q13. what is meant by poor in this context? Reduced?], including antidepressants, aspirin, antihistamines, diuretics, beta-blockers, post-menopausal oestrogen therapy, corticosteroids and atropine eye drops (Törnquist 2012). Additional causes include a loss of sensory drive to the lacrimal gland that occurs in herpes zoster ophthalmicus, and overuse of anaesthetic eye drops (Törnquist 2012).

\section{Management}

Replacement teardrop therapy, treating the underlying cause and maintaining optimum lid hygiene are important to prevent complications, promote ocular comfort and preserve sight. A diet rich in omega 3 and 6 is recommended to maintain healthy meibomian oil secretion. Therefore, oily fish such as salmon and tuna should be recommended (Royal National Institute of the Blind 2016). Patients who are vegetarian may benefit from adding flaxseed to their daily diet (Royal National Institute of the Blind 2016). Dry eye is problematic and requires effective management in an eye clinic to prevent blindness.

\section{Conjunctivitis}

Conjunctivitis is the most common cause of red eye (Cronau et al 2010). Infectious conjunctivitis is classified as bacterial, viral, chlamydial and fungal (Yanoff and Duker 2013), of which bacterial and viral infection are the most common types.

Chemical irritants, traditional eye remedies or allergy should be ruled out [Q14. could we say 'should be investigated as possible causes', rather than ruled out?]. Table 1 lists the causes of conjunctivitis and how they primarily affect various age groups.

\begin{tabular}{|c|c|c|c|}
\hline & New-born babies & Children & Adults \\
\hline Viral infection & Uncommon & Usually affects both eyes & Usually affects both eyes \\
\hline Bacterial infection & $\begin{array}{l}\text { May be severe and sight- } \\
\text { threatening }\end{array}$ & $\begin{array}{l}\text { May affect one or both } \\
\text { eyes. May be severe and } \\
\text { sight-threatening }\end{array}$ & $\begin{array}{l}\text { May affect one or both } \\
\text { eyes. May be severe and } \\
\text { sight-threatening }\end{array}$ \\
\hline Chlamydia & Can cause conjunctivitis & $\begin{array}{l}\text { Causes trachoma, which } \\
\text { usually affects both eyes }\end{array}$ & Usually affects both eyes \\
\hline Allergy & Uncommon & Usually affects both eyes & Uncommon \\
\hline Chemical irritants & Uncommon & Can affect one or both eyes & Can affect one or both eyes \\
\hline Traditional eye remedies & Uncommon & Can affect one or both eyes & Can affect one or both eyes \\
\hline \multicolumn{4}{|c|}{$\begin{array}{l}\text { (Senaratne and Gilbert 2005) [Q15. note: some wording changes made in accordance with the reference. Do you have } \\
\text { permission to reproduce this table in your article?] }\end{array}$} \\
\hline
\end{tabular}

Bacterial conjunctivitis (Figure 8), commonly caused by S. aureus, is characterised by a rapid onset of bilateral red eyes, lid swelling and a purulent yellow discharge (Watkinson 2013). The patient's vision and pupil response are unaffected, unless the cornea becomes infected (Yanoff and Duker 2013). It is important that the nurse is thorough when assessing patients presenting with a red eye, since an accurate diagnosis is essential to initiate appropriate treatment or referral to a clinic. Marsden (2011) emphasised the use of triage for patients who attend with a red eye, to avoid unnecessary delay for [Q16. treatment and management of?] emergency red eye conditions, for example gonococcal conjunctivitis. 


\section{Figure 8. Acute bacterial conjunctivitis}

[Ed note: figure to be re-used from Watkinson 2013]

Conjunctivitis may settle by itself in most adult patients. However, babies presenting with a purulent greenish yellow discharge and swollen lids should be classified as an emergency because Gram-negative Neisseria gonococcus can penetrate the intact epithelium and progress rapidly to corneal perforation and sight loss (Yanoff and Duker 2013). Conjunctivitis in new-born babies [Q17. where new-born babies is used, ok to change to neonates?] is referred to as ophthalmia neonatorum. Prompt treatment with local and systemic antibiotic therapy will improve the condition. The mother and her sexual partner should also be treated with a systemic antibiotic (Marsden 2011).

\section{Management}

Patients with acute bacterial conjunctivitis are prescribed topical antibiotics to speed recovery (Marsden 2011). It is the nurse's responsibility to inform patients about the highly contagious nature of the condition (Watkinson 2013). Therefore, it is important that all patients and their parents are given written information on the precautionary care required to prevent spread of the disease to others. For example, this might include keeping the patient's toiletries, towels and face flannels separate from those of other family members. Paper tissues should be used and disposed of after a single use and the importance of hand washing before and after the instillation of antibiotic eye drops should be reinforced (Watkinson 2013). The patient should also be advised to wear dark glasses for comfort, but the use of an eye pad is not recommended (Watkinson 2013).

\section{Health promotion}

Promoting health is an essential nursing responsibility, and this should be patient-centred, empowering and tailored to the patient and their diagnosis (Nursing and Midwifery Council 2015). Following ocular assessment and diagnosis, the nurse has a duty to educate patients and relevant others about the nature of the ocular condition (Marsden 2017) and advise about promoting recovery or healing (Tallouzi 2011). For example, healthy eating is essential for ocular health. It is important to consider pain management in inflammatory eye conditions. Health education information should also be given to ensure the patient understands how to use medication before leaving the clinic (Marsden 2011). In PAACG, patients should be taught how to use the eye drops until their surgery. Teaching the principles of hygiene is vital in infected cases of red eye. Furthermore, if the pupil is dilated, the patient should be advised about the hazards of driving (Marsden 2017).

\section{Conclusion}

Nursing skills and responsibilities involved in establishing accurate diagnosis of red eye and making prompt referral for appropriate treatment is pivotal to relieving ocular pain, restoring vision or preventing potential sight loss. If diagnosis is unclear, referral to an ophthalmologist is essential to avoid adverse visual consequences. The five main ocular conditions giving rise to a red eye are PAACG, acute iritis, dry eye, chronic blepharitis and conjunctivitis. It is important for the nurse to be able to recognise the signs and symptoms of such conditions. More significantly, the nurse should be able to distinguish between a sight-threatening and non-sight-threatening ocular condition and take appropriate action. The nurse's role remains vital in addressing the challenges associated with the care and management of patients with a red eye and preventing the possibility of sight loss.

\section{References}

Azuara-Blanco A, Burr J, Ramsay C et al (2016) Effectiveness of early lens extraction for the treatment of primary angleclosure glaucoma (EAGLE): a randomised controlled trial. The Lancet. 388, 10052, 1389-1397. 
Batterbury M, Bowling B, Murphy C (2009) Ophthalmology. An Illustrated Colour Text. Third edition. Elsevier, Edinburgh.

Bowling B (2015) Kanski's Clinical Ophthalmology: A Systematic Approach. Elsevier Health Sciences, London.

British National Formulary (2017) British National Formulary. No. 73. BMJ Group and the Royal Pharmaceutical Society of Great Britain, London.

Cronau H, Kankanala RR, Mauger T (2010) Diagnosis and management of red eye in primary care. American Family Physician. $81,2,137-144$.

Din N, Patel NN (2012) Blepharitis - a review of diagnosis and management. International Journal of Ophthalmic Practice. 3, $4,150-155$.

Foulks GN (2007) DEWS Report: a mission completed. Ocular Surface. 5, 2, 65-66.

Jackson WB (2008) Blepharitis: current strategies for diagnosis and management. Canadian Journal of Ophthalmology. 43, 2, 170-179.

Marsden J (2011) Red eye: presentation, disease process and evidence-based care. International Journal of Ophthalmic Practice. 2, 2, 80-88.

Marsden J (Ed) (2017) Ophthalmic Care. Second edition. M\&K Publishing, Cumbria.

National Institute for Health and Care Excellence (2015) Blepharitis: Prevalence.

cks.nice.org.uk/blepharitis\#!backgroundsub:2 (Last accessed: 8 November 2017.)

Nursing and Midwifery Council (2015) The Code: Professional Standards of Practice and Behaviour for Nurses and Midwives. NMC, London.

Riordan-Eva P, Cunningham ET Jr (2011) Vaughan \& Asbury’s General Ophthalmology. 18th edition. McGraw-Hill Medical, New York NY.

Royal National Institute of the Blind (2016) Nutrition and the Eye. www.rnib.org.uk/eye-health/looking-after-youreyes/nutrition-and-eye (Last accessed: 8 November 2017.)

Schaumberg DA, Dana R, Buring JE et al (2009) Prevalence of dry eye disease among US men: estimates from the Physicians' Health Studies. Archives of Ophthalmology. 127, 6, 763-768.

Seewoodhary M (2009) Eye emergencies - accident and emergency ophthalmic practice. In Watkinson S (Ed) Issues in Ophthalmic Practice: Current and Future Challenges. M\&K Publishing, Cumbria, 47-90.

Seewoodhary M, Awelewa C (2014) Common external eye disorders in older people. In Watkinson S (Ed) Older People with Visual Impairment: Clinical Management and Care. M\&K Publishing, Cumbria, 101-124.

Senaratne T, Gilbert C (2005) Conjunctivitis. Community Eye Health Journal. 18, 53, 73-75.

Shaw ME, Lee A (2016) Ophthalmic Nursing. Fifth edition. CRC Press, Boca Raton FL.

Tallouzi M (2011) Chlamydial conjunctivitis: presentation and investigations. International Journal of Ophthalmic Practice. 2 , $3,139-143$.

The College of Optometrists (2016) Blepharitis (Lid Margin Disease). Version 14. The College of Optometrists, London.

Törnquist AL (2012) Dry eye disease: simple to diagnose but complex to manage. International Journal of Ophthalmic Practice. 3, 5, 194-202.

Watkinson S (2013) Assessment and management of patients with acute red eye. Nursing Older People. 25, 5, 27-34.

Watkinson S (Ed) (2014) Older People with Visual Impairment: Clinical Management and Care. M\&K Publishing, Cumbria.

Williamson S, Seewoodhary R (2013) Cataract blindness in older people and sight restoration: a reflection. International Journal of Ophthalmic Practice. 4, 5, 212-218.

Yanoff M, Duker JS (Eds) (2013) Ophthalmology. Fourth edition. Saunders Elsevier, Philadelphia PA. 